\title{
Correction to: The association between 2,4-D and serum testosterone levels: NHANES 2013-2014
}

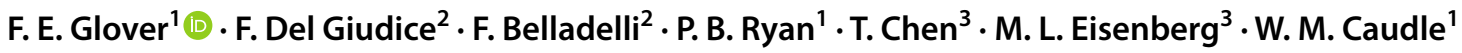

Published online: 5 January 2022

(C) Italian Society of Endocrinology (SIE) 2021

\section{Correction to: Journal of Endocrinological Investigation https://doi.org/10.1007/s40618-021-01709-y}

The first and second author names have been incorrectly published in the original publication. The complete correct names should read as follows respectively.

First author:

F. E. Glover

Second author:

F. Del Giudice

The original article has been corrected.

Publisher's Note Springer Nature remains neutral with regard to jurisdictional claims in published maps and institutional affiliations.

The original article can be found online at https://doi.org/10.1007/ s40618-021-01709-y.

\section{F. E. Glover}

gloverfrank975@gmail.com

1 Gangarosa Department of Environmental Health, Rollins School of Public Health, Emory University, Atlanta, GA 30322, USA

2 Department of Maternal-Infant and Urological Sciences, "Sapienza" Rome University, Policlinico Umberto I Hospital, Rome, Italy

3 Department of Urology, Stanford University School of Medicine, Stanford, CA 94305, USA 